\title{
Desempenho de escolas públicas na Olimpíada Brasileira de Matemática na cidade de Paulista, Paraíba
}

\section{Performance of public schools in the Brazilian Mathematical Olympiad in the city of Paulista, Paraíba, Brazil}

\author{
Roberta de Medeiros Gadelha \\ Especialista em Ensino de Matemática, Universidade Cândido Mendes. E-mail: robertamgadelha@ hotmail.com \\ Emerson Erick Vieira da Silva \\ Especialista em Ensino de Química, Universidade Cândido Mendes. E-mail: emersonfis@ @otmail.com \\ Everton Vieira da Silva \\ Doutor em Química, Universidade Federal de Campina Grande. E-mail: evertonquimica@hotmail.com \\ Sheila da Silva \\ Especialista em Ensino de Química, Universidade Cândido Mendes, E-mail: sheila_ida@ hotmail.com \\ Vilmar Vaz da Silva \\ Professor Mestre em Matemática, Universidade Estadual da Paraíba. E-mail: vilmarvazsilva@ gmail.com
}

\begin{abstract}
Resumo: No ano de 2005, aconteceu a primeira edição de uma das olimpíadas brasileiras de maior destaque nacional, abrangendo milhões de estudantes a cada ano, a OBMEP (Olimpíada Brasileira de Matemática das Escolas Públicas), promovida pelo Ministério da Educação (MEC) e pelo Ministério da Ciência e Tecnologia (MCT) com o apoio do Instituto de Matemática Pura e Aplicada (IMPA) e pela Sociedade Brasileira de Matemática (SBM), sendo estes responsáveis por sua organização e direção, possuindo como principais objetivos o estímulo ao estudo da matemática, a melhoria do ensino em todo país, aperfeiçoamento e valorização profissional dos professores, entre outros fatores. Nesse sentido, este estudo teve como objetivo analisar às principais características dessa olimpíada, dando ênfase aos resultados obtidos por uma cidade do interior nordestino, Paulista, Paraíba, durante as dez primeiras edições da OBMEP, visto que, nos últimos anos, os estudantes paulistenses conseguiram um grande destaque na mídia brasileira, devido às premiações alcançadas que, superaram outras cidades economicamente mais evoluídas do estado. Foram realizadas entrevistas com 03 (três) alunos que obtiveram premiações nessa olimpíada, e também, com a professora representante da OBMEP na cidade, com o intuito de obter informações em relação aos estudos preparatórios dos estudantes para a realização da mesma, além da coleta e verificação dos dados obtidos durante algumas edições da OBMEP em Paulista-PB. Houve uma grande mudança na elaboração das aulas de matemática, que se tornaram mais práticas e relacionadas ao cotidiano dos discentes, além disso, os projetos extracurriculares contribuíram para a dedicação e sucesso dos alunos nessas competições matemáticas.
\end{abstract}

Palavras-chave: Olimpíada Brasileira; Estudo da Matemática; Melhoria no Ensino.

Abstract: In 2005, the first edition of one of the most prominent Brazilian Olympiads took place, covering millions of students each year, the OBMEP (Brazilian Mathematics Olympiad of Public Schools) promoted by the Ministry of Education (MEC) and the Ministry of Education (MCT) with the support of the Institute of Pure and Applied Mathematics (IMPA) and the Brazilian Society of Mathematics (SBM), which are responsible for its organization and direction, with the main objectives being to stimulate the study of mathematics, the improvement of teaching in all countries, the improvement and professional appreciation of teachers, among other factors. In this sense, this study aimed to analyze the main characteristics of this Olympiad, emphasizing the results obtained by a city in the interior of the Northeast, Paulista-PB, during the first ten editions of OBMEP, since, in recent years, students from São Paulo achieved a great highlight in the Brazilian media, due to the awards that have surpassed other economically more developed cities in the state. Interviews were conducted with 03 (three) students who obtained awards in this Olympics, and also with the teacher representing the OBMEP in the city, with the purpose of obtaining information regarding the preparatory studies of the students for the accomplishment of the same, besides the collection and verification of data obtained during some issues of OBMEP in Paulista-PB. There was a great change in the elaboration of the mathematics classes, which became more practical and related to the students' daily life, in addition, the extracurricular projects contributed to the dedication and success of the students in these mathematical competitions.

Key words: Brazilian Olympiad; Study of Mathematics; Improvement in Teaching. 


\section{INTRODUÇÃO}

O processo de ensino e aprendizagem da Matemática vem se transformando em uma tarefa cada vez mais complexa, esta se encontra tão mesclada com cotidiano que algumas vezes passa despercebida. Não há como compreender por que o uso da matemática em um ambiente escolar se torna tão temido e cheio de bloqueios se, usualmente estamos utilizando-a para negociar, ter noção de tempo e espaço e em muitas outras situações comuns da rotina de qualquer ser humano.

Segundo Almeida (2006) os aprendentes demonstram uma verdadeira aversão em aprender matemática, muitas vezes pelo simples fato da disciplina ser considerada complexa e com isso, passam a expor que não existe identificação pessoal com o componente curricular. No entanto, tais dificuldades podem está relacionas com fatores mentais, psicológicos e principalmente pedagógicos, onde o educador deve buscar diferentes práticas que possam contribuir para o encantamento do educando e consequentemente uma aprendizagem significativa.

Logo, uma boa educação se faz em diálogos e trocas de ideias e informações entre o alunado e o educador, para que a educação possa fluir de forma satisfatória, deve acontecer uma interação entre ambas as partes, uma aprendizagem mútua. $\mathrm{O}$ papel do professor vem se transformando no decorrer do tempo, além de organizador da aprendizagem, este necessita conhecer as condições socioculturais e a competência cognitiva dos alunos, escolhendo questões que possibilitem uma construção do conhecimento, conforme PCN's (1998).

O educador, principalmente de escola pública, encontra-se em meio a turmas numerosas, com vários níveis de aprendizado, uns com bastante deficiência e outros com uma capacidade incrível de aprendizado. Nesse contexto, se o professor não estiver adequadamente qualificado, não conseguirá instigar seus alunos no processo educacional. Com um ensino desqualificado, os alunos não aprendem e não se sentem motivados, não conseguindo relacionar os conteúdos com o cotidiano, por isso que, se faz extremamente necessário o planejamento adequado das aulas, procurando sempre levar os alunos a pensar, justificar e produzir seus próprios resultados (MARASINI, 2000).

Muitos recursos são propostos para o efetivo melhoramento do ensino de matemática, um deles consiste nas Olimpíadas de Matemática, como exemplo a OBMEP (Olimpíada Brasileira de Matemática das Escolas Públicas) que são competições repletas de prêmios e oportunidades de bolsas em programas bastante conceituados, incentivando tanto a dedicação dos estudantes na disciplina como também ajudando os docentes no ensino da mesma, trabalhando questões mais comuns que possam ser aplicadas no dia a dia.

As Olimpíadas de Matemática buscam o melhoramento do ensino de matemática para o efetivo aprendizado, incentivando a escola como um todo, dando oportunidades únicas aos jovens talentos da área, impulsionando-os para uma carreira promissora nas ciências exatas e tecnológicas.

A OBMEP abrange estudantes da rede pública do $6^{\circ}$ (sexto) ao $9^{\circ}$ (nono) ano do Ensino Fundamental, e também todos os estudantes do Ensino Médio, além dos alunos da EJA (Educação de Jovens e Adultos). A mesma conta com premiações de medalhas de ouro, prata, bronze e menções honrosas, também sendo oferecidas Bolsas no Programa de Iniciação Cientifica Junior. (PIC), que se realiza através de uma rede nacional de professores, situados em escolas e universidades, visando treinar e preparar os alunos para a resolução de problemas, motivando-os para uma carreira científica e tecnológica. Os bolsistas ganham um incentivo mensal oferecido pelo CNPq (Conselho Nacional Científico e Tecnológico), sendo realizados encontros presenciais dirigidos com material de apoio e orientações de estudo.

Em 2013, a mesma contou com a participação de quase 19 milhões de alunos, espalhados por vários municípios brasileiros. Sendo assim, a cada edição realizada, esse tipo de competição escolar torna-se mais abrangente, atingindo cidades pequenas do interior e chamando a atenção do país para as mesmas. Como exemplo, temos o município de Paulista-PB, que alcançou uma grande repercussão devido as suas ótimas premiações na OBMEP, nesse sentido, este estudo tem o objetivo analisar às principais características dessa olimpíada, dando ênfase aos resultados obtidos pela cidade, procurando ressaltar alguns fatores que possam ter contribuído para a aquisição dos mesmos.

\section{MATERIAL E MÉTODOS}

Este estudo fundamenta-se em pesquisas bibliográficas e em pesquisa de campo que em concordância com Gil (2008), esse tipo de estudo é realizado com um único grupo, observado diretamente por um pesquisador que possui dados sobre um determinado assunto no local. A pesquisa foi realizada no município de Paulista na Paraíba, localizado no interior do estado, contando com 11.783 habitantes no último censo realizado em 2010, de acordo com o Instituto Brasileiro de Geografia e Estatística (IBGE).

O trabalho foi realizado com aspectos de natureza quantitativa e qualitativa, pois as mesmas se complementam na busca de informações expressivas. Um dos instrumentos utilizados para a coleta de informações foi à entrevista, um aplicada com a professora representante da OBMEP e outra com 03 (três) alunos premiados com medalhas e menções honrosas em algumas edições.

A entrevista aplicada com os alunos foi constituída por 03 (três) questões discursivas (subjetivas), que foram organizadas de forma a obter o máximo de informações para análise. Abordando temas como a participação e interesse dos mesmos em competições matemáticas, em especial a OBMEP.

Ocorreu também entrevista com uma professora representante da OBMEP no município, que foi formulada em 11 (onze) questões também discursivas sobre sua atuação na área de matemática. As duas entrevistas realizadas buscaram como finalidade a aquisição de informações com aspectos qualitativos.

Além disso, teve-se o acesso a tabelas, reportagens, entre outros materiais de arquivo pessoal para o enriquecimento desta pesquisa por parte da professora 
entrevistada e representantes Regionais da OBMEP, tendo como propósito a aquisição de dados quantitativos para a elaboração de gráficos, que foram verificados e analisados de forma criteriosa, buscando sempre a comprovação do nível de desempenho adquirido pelos estudantes do município de Paulista-PB nas competições de matemática.

\section{RESULTADOS E DISCUSSÃO}

Ao longo das edições da OBMEP, os estudantes de Paulista-PB conseguiram obter colocações importantes nessa olimpíada, fazendo com que a cidade ganhasse um grande destaque nacional, incentivando ainda mais os alunos a se dedicarem ao estudo da matemática. No primeiro ano foram 07 (sete) menções honrosas, premiação bastante importante e comemorada pelas famílias dos discentes. No ano de 2009, obteve-se à primeira medalha da cidade (bronze) (Figura 1). No ano seguinte (2010) observa-se na figura lque ocorreu o registro da primeira medalha de ouro para o município. No ano de 2012, verifica-se que os estudantes das escolas publicas do município de Paulista alcançaram um total de 22 (vinte e duas) premiações, sendo: 12 (doze) menções honrosas, 03 (três) medalhas de bronze, 02 (duas) de prata e 05 (cinco) de ouro, consistindo na melhor premiação alcançada pelo município em todas as edições realizadas (Figura 1).

Figura 1. Resultados do Município de Paulista, Paraíba, na Olimpíada Brasileira de Matemática das Escolas Públicas

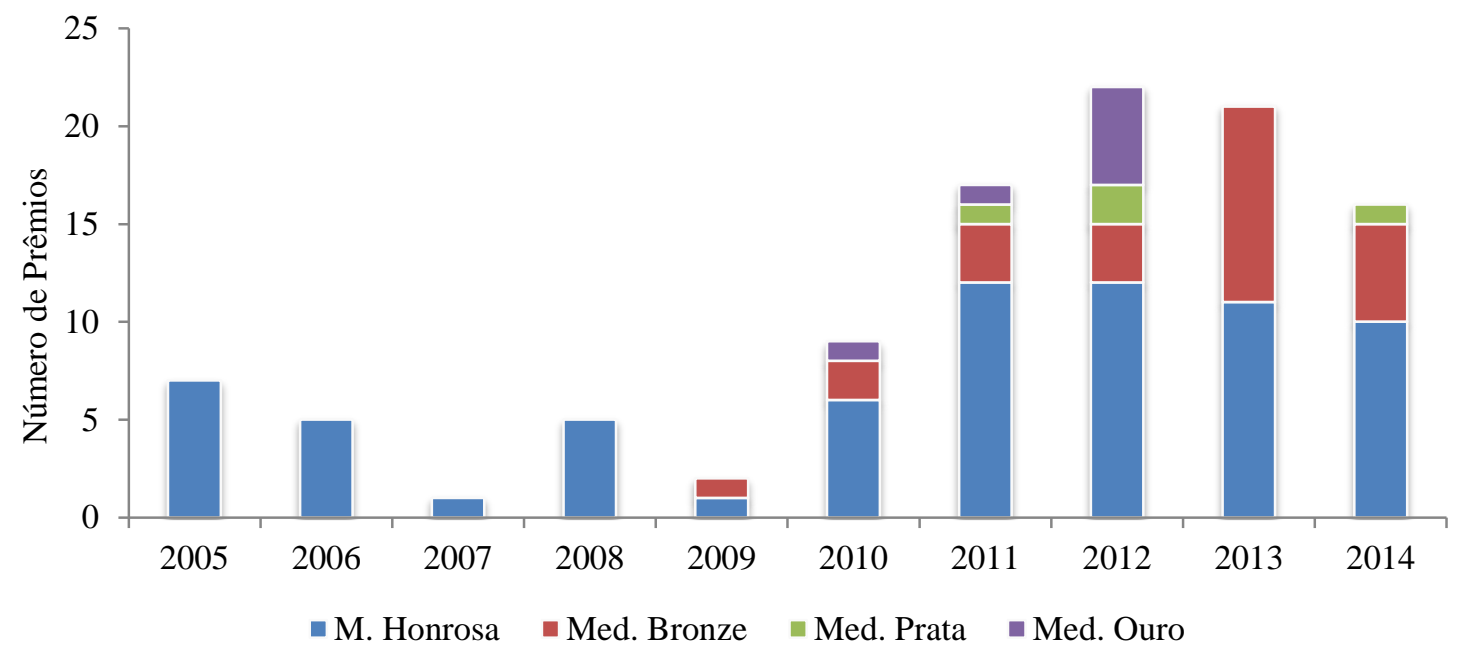

Este fato repercutiu nas principais emissoras de comunicação do país, trazendo muitos jornalistas para a cidade e fazendo com que a mesma ficasse conhecida como "A capital da Matemática".

A maneira como os alunos se preparavam para a competição proporcionou meios para a obtenção das premiações, pois com uma metodologia um pouco mais diversificada e totalmente voltada para a realidade dos estudantes, a assimilação dos conteúdos matemáticos tornou-se mais fácil. $\mathrm{O}$ uso de aulas práticas e a dedicação aos estudos em horário oposto ao escolar proporcionaram conquistas acadêmicas importantes na vida dos estudantes do município.

Masetto (2001) afirma que por mediação pedagógica entendemos a atitude, o comportamento, do professor que se coloca como facilitador, incentivador ou motivador da aprendizagem, que se apresenta com a disposição de ser uma ponte entre o aprendiz e sua aprendizagem não uma ponte estática, mas uma ponte 'rolante', que ativamente colabora para que o aprendiz chegue aos seus objetivos.

Observa-se que, no período de 2006 a 2009, o número de premiações não era tão expressiva como os resultados alcançadas pelo município a partir do ano de 2010 (Figura 1). Segundo relato de uma professora representante da OBMEP o fato está relacionado à preparação especifica para os alunos que passou a ser adotada no município (Quadro1).
Quadro 1. Relato de uma professora municipal sobre a preparação para Olimpíada Brasileira de Matemática das Escolas Públicas na cidade de Paulista, Paraíba

"Nesse período, não havia uma preparação
específica para as Olimpíadas de
Matemática, os alunos que passassem para
a segunda fase da mesma, tinham que
estudar sozinhos. Apenas no ano de 2010,
iniciei dando aulas preparatórias para os
alunos que se interessassem."

Em seu planejamento, a professora analisa como trabalha o conteúdo em sala de aula e, se possível, sempre realiza aulas práticas conciliando com a teoria, dessa forma, há um aprendizado consistente, em que os estudantes irão exercitar de forma descontraída as informações que os livros didáticos possuem. Como por exemplo, para lecionar números decimais, a professora levou sua turma para um posto de gasolina da cidade, em que os alunos aprenderam a desenvolver questões de proporção, razão, regra de três, além de desenvolver seu lado interpretativo de situações comuns do cotidiano. As praticas também foram realizadas em pizzaria, feira livre, farmácias, mercados, entre outros lugares como destaca a professora (Quadro 2). 
Quadro 2. Relato de uma professora municipal sobre a importância da realização de aulas práticas no ensino de matemática em escolas públicas na cidade de Paulista, Paraíba

"O aprendizado é mais significativo quando
as aulas teóricas são subsidiadas das aulas
práticas. É onde o aluno entende a utilidade
dos conteúdos e a partir daí, desperta o
interesse para as Olimpíadas; eles passam
a estudar mais e aprender mais. "

Baur (2009) expõe que situações matemáticas concretas são obviamente mais fáceis de assimilar do que as situações matemáticas abstratas, uma vez que é mais natural entendermos o que conhecemos e o que faz parte do nosso dia-a-dia, do que compreendermos algo que não faz parte da nossa realidade. Primeiramente o estudante deve se familiarizar com as situações reais, as situações relacionadas ao cotidiano, e através destas situações, o aluno poderá fazer conjecturas e previsões de forma mais generalizada.

Com suas formas diversificadas de lecionar, Paulista alcançou patamares elevados na OBMEP nos anos de 2010 a 2013, como observa-se na Figura 1. Entretanto, em 2014, houve novamente uma queda nos resultados e premiações alcançadas pelos estudantes, em relação a esse fato, a professora entrevistada destaca alguns fatores que possam ter ocasionado esse desempenho (Quadro 3).

Quadro 3. Relato de uma professora municipal sobre o desempenho no ano de 2014 na Olimpíada Brasileira de Matemática das Escolas Públicas dos estudantes da cidade de Paulista, Paraíba

"O primeiro deles é que, o nível dessa
competição aumenta gradativamente a cada
edição realizada, exigindo mais esforço e
dedicação dos estudantes. O segundo fator
é que devido ao grande sucesso, muitos
alunos paulistenses que haviam sido
premiados em todas as edições ganharam
bolsas de estudo e foram morar em outras
cidades. Houve também uma queda na
frequência das aulas preparatórias, devido
principalmente, ao espaço físico onde era
realizada, antigamente, eu dava aulas
preparatórias em minha residência,
conforme o aumento do número de alunos
interessados, houve a necessidade de
desenvolver esse trabalho na própria
Escola, e esta se encontrava em reforma
desde o início de 2014."

O desempenho abaixo observado no ano de 2014 pode ser relacionado a pouca regularidade das aulas preparatórias, assim demostrando que essas aulas extras são imprescindíveis para os estudantes que possuem o objetivo de alcançarem uma boa colocação tanto na OBMEP como em qualquer disputa acadêmica, sendo que a dedicação e a revisão dos conteúdos devem ser diariamente reforçadas, observa-se essas questões no relado dos estudantes sobre as atividades desenvolvidas durante a preparação para a OBMEP (Quadro 4).
Quadro 4. Relato de estudantes de escola pública da cidade de Paulista sobre preparação para Olimpíada Brasileira de Matemática das Escolas Públicas

"Eu acredito que a prática que a professora fazia fora da sala de aula, nos levando para outros lugares da cidade e também, os problemas divertidos propostos nos exercícios, nos ajudavam a aprender de uma forma não tão séria quanto numa sala de aula, dessa forma, a gente estudava matemática de acordo com o nosso ambiente, com o nosso dia a dia e ficava bem mais fácil” (ALUNO A).

"Nós passamos a ver a matemática não só como uma disciplina, começamos a estudála mais profundamente no programa de iniciação cientifica, e também as aulas divertidas da nossa professora, que eram as aulas práticas e alguns projetos, fizeram com que a nossa curiosidade fosse aumentando, fazendo com que tudo ficasse mais divertido" (ALUNO B).

"A matemática é meio que um desafio para a gente e, sempre que a gente se sente desafiado, queremos vencer aquilo, ganhar aquele desafio. A OBMEP $e$ as aulas da nossa professora faziam a gente ver a matemática no nosso cotidiano e, isso nos incentivou bastante, a gente passou a ter mais gosto pela matéria e a prática ajuda muito, resolver várias questões faz com que a gente realmente aprenda o conteúdo e não apenas decore a matéria. Por que matemática é isso, é só você praticar bastante" (ALUNO C).

Segundo Bagatini (2010) ao aplicar o que fora trabalhado em sala, o aluno vê a utilidade do que fora feito [...] passando a ter uma aprendizagem que faça realmente sentido.

O Programa de Iniciação Cientifica Júnior (PIC), desenvolvido por professores da Universidade Federal de Campina Grande (UFCG) no município, foi de extrema ajuda no processo de estudo para realização da segunda fase da OBMEP, pois serviu como um complemento, em que os alunos estudavam questões de edições passadas da competição, deixando-os habituados ao nível de complexidade das mesmas. Além disso, a professora representante da OBMEP no município também reunia seus alunos em horário oposto às aulas escolares, para reforço e também trabalhar questões da olimpíada, sendo que o horário escolar não era suficiente para o desenvolvimento de todas as atividades. Todos esses processos colaboraram para a conquista de várias premiações.

Diante de resultados tão expressivos, muitas oportunidades surgiram para os estudantes premiados, como bolsas de estudo em renomadas escolas, reconhecimento perante a sociedade, além de poderem conhecer novos ambientes e fazerem amigos que também estavam passando pelo mesmo momento, tendo bastante influência na vida dos alunos e dos familiares (Quadro 5). 
Quadro 5. Relato de estudantes de escola pública da cidade de Paulista sobre as conquistas com a Olimpíada Brasileira de Matemática das Escolas Públicas

"Eu acredito que a minha participação na
OBMEP e a dos meus colegas foi uma
maneira de crescer, tanto nós mesmos
quanto a cidade, por que Paulista ficou
conhecida mesmo. A OBMEP influenciou
em tudo na minha vida, as entrevistas, as
premiaçoses, muitas amizades que a gente
fez pelo Brasil inteiro e, além disso, a união
que a gente adquiriu, pois nós estudávamos
todos os dias juntos, então nos tornamos
uma família [...]" (ALUNO A).
"[...] a OBMEP trouxe muitas
oportunidades, muitas chances apareceram
na nossa vida, tivemos a oportunidade de
viajar e conhecer novas pessoas e projetos
bastante interessantes que só contribuíram
para nossa preparação [...]" (ALUNO B).
"Realmente a OBMEP nos abriu portas
muito boas que a gente aproveitou muito:
estudar fora, intercâmbios e isso foi muito
interessante. [...] A cada ano a gente ia se
aprimorando mais e buscando melhorar
nessa área [...]" (ALUNO C).

A Olimpíada Brasileira de Matemática das Escolas Públicas (OBMEP) é um projeto de extrema importância para a qualidade do ensino de matemática do país, pois o mesmo vem incentivando estudantes a se dedicarem ao estudo dessa área. Além disso, as olimpíadas de matemática vêm contribuindo e facilitando a elaboração de aulas mais dinâmicas e atrativas pelos docentes, promovendo o uso de materiais de apoio complementares durante as aulas. Dessa forma, o ensino torna-se mais prático e condizente com a realidade de cada região.

Além disso, a OBMEP proporcionou a criação de vários projetos que estimulam tanto os professores como os alunos no desenvolvimento de uma educação mais sólida, permitindo-se enxergar oportunidades de crescimento intelectual e profissional para todos os envolvidos no processo.

Destaca-se ainda, a vital contribuição da OBMEP na vida de todos os paulistenses, fazendo com que todo o Brasil pudesse prestigiar os resultados alcançados pelos estudantes da cidade, dando ênfase ao trabalho dos profissionais da área e entusiasmando os alunos a buscarem resultados ainda melhores. Contudo, a educação é um processo árduo e que necessita de constantes progressos, fazendo-se indispensáveis mais investimentos financeiros para a criação de novos programas que possam auxiliar no avanço não só da matemática, mas de toda disciplina curricular que seja essencial para a sociedade.

\section{CONCLUSÕES}

A educação é um instrumento que pode modificar pessoas, cidades e toda a realidade de um país. O município de Paulista no Estado da Paraíba necessita intensificar os estudos de preparação para as Olimpíadas Brasileira de Matemática das Escolas Públicas para que haja resultados ainda mais relevantes, contudo, as experiências iniciais mostram resultados satisfatórios e comprova-se a cada edição.

\section{REFERÊNCIAS}

ALMEIDA, C. S. Dificuldades de Aprendizagem em Matemática e a percepção dos professores em relação a fatores associados ao insucesso nesta área. Tcc de Licenciatura em Matemática, UCB, 2006.

ALVES, W. J. S. O Impacto da Olimpíada de Matemática em Alunos da Escola Pública. 2010. 30 p. Dissertação (Mestrado Profissional em Ensino de Matemática), Pontifícia Universidade Católica de São Paulo PUC/SP, São Paulo, 2010.

BAGATINI, A. Olimpíadas de Matemática, Altas Habilidades e Resolução de Problemas. 2010. 82 p. Monografia (Graduação em Matemática), Departamento de Matemática Pura e Aplicada do Instituto de Matemática, Universidade Federal do Rio Grande do Sul, Porto Alegre, 2010.

BAUR, A. O ensino-aprendizagem de matemática através da resolução de problemas. [Trabalho de Conclusão de Curso] Instituto de Matemática. Universidade Federal do Rio Grande do Sul. Porto Alegre, 2009.

BRASIL, 2014. Ministério da Educação. Olimpíada Brasileira de Matemática. Disponível em: <http://www.obm.org.br/opencms/>. Acesso em: $15 / 11 / 2015$.

BRASIL. Ministério da Educação. Olimpíada de Matemática das Escolas Públicas. Disponível em: <http://www.obmep.org.br/>. Acesso em: 05/10/2015.

BRASIL. Ministério da Educação. Portal Brasil. Disponível em: <http://www.brasil.gov.br/>. Acesso em: 06/10/2015.

BRASIL. Secretaria de Educação Fundamental. Parâmetros Curriculares Nacionais: Matemática/Secretaria de Educação Fundamental. Brasília: MEC/SEF, 1998. 148 p.

GIL, A. C. Como Elaborar Projetos de Pesquisa. São Paulo: Atlas, 2008.

LAKATOS, E. M.; MARCONI, M. D. A. Fundamentos de metodologia científica. 5 ed., São Paulo: Atlas, 2003.

MARASINI, S. M. Contribuições da Didática da Matemática para a Educação matemática. In: RAYS, Oswaldo Alonso. Educação e ensino: constatações, inquietações e proposições. Santa Maria: Pallotti, 2000.

MASETTO, M. T. Competência pedagógica do professor universitário. São Paulo: Summus, 2001.

ONUCHIC, L. R. Ensino-Aprendizagem de Matemática através de Resolução de Problemas. In: BICUDO, M. A. V. Pesquisas em Educação Matemática. São Paulo: Editora UNESP, 1999, 199-220.

VILA, A.; CALLEJO, M. L. Matemática para aprender a pensar: o papel das crenças na resolução de problemas. Porto Alegre: Artmed, 2006. 